\title{
Resumen de tesis: Estrellas y amapolas. Las pinturas rurales de Prilidiano Pueyrredón y las sensibilidades en el Buenos Aires de $1860^{1}$
}

\author{
Lucas Andrés Masán \\ (CIEP- Universidad Nacional del Centro de la Provincia de Buenos \\ Aires, CONICET) \\ andresmasan@gmail.com
}

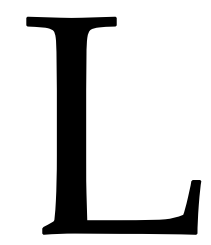

a tesis doctoral, cuyo resumen presentamos aquí, se enmarca dentro de una tradición historiográfica que busca situar en el centro de la escena a las imágenes. Considerando al material visual como insumo valioso que permite "imaginar" el pasado de un modo más vívido y con potencialidades diferentes a las de los textos escritos (Burke, 2005 y 2008), empleamos las pinturas rurales de Prilidiano Pueyrredón (1823-1870) como un vector para analizar la modelación de la sociedad porteña durante la década de 1860. El objetivo de investigación persiguió una doble finalidad, indagando en el modo en que las sensibilidades son encarnadas en las pinturas y cómo estas promovieron imaginaciones sobre el ámbito al que aludieron. Buscamos, en definitiva, adentrarnos en el estudio de las sensibilidades (Corbin, 1987; Barrán, 1990; Vigarello, 1991; Farge, 2008, entre otros) a través de un aspecto caro a la modernidad, procurando examinar la actividad visual del pasado (Baxandall, 1978) junto a los mecanismos comprometidos en su elaboración.

Por tratarse de un examen histórico que conecta las imágenes con su tiempo, se atendió no solo a la construcción social de lo visual sino también a la configuración visual de lo social (Mitchell, 2005, p. 16). En este sentido, la hipótesis principal de la tesis es que las pinturas, entendidas como actos icónicos (Bredekamp, 2017), condensaron un conjunto de pautas y operaciones de una comunidad que se veía e imaginaba con criterios renovados.

\footnotetext{
${ }^{1}$ Tesis de doctorado en Historia defendida el 3 de diciembre de 2020 en la Universidad Nacional de La Plata. Realizada bajo la dirección de la Dra. Mónica Blanco (CIEP-UNICEN, CONICET), la codirección del Dr. Jorge Troisi Meleán (UNLP) y financiada mediante beca doctoral de CONICET (2017-2021). El jurado estuvo compuesto por la Dra. Sandra Fernández (ISHiR-UNR, CONICET), el Dr. Emir Reitano (UNLP) y el Dr. Tomás Sansón Corbo (UDELAR). Calificación: 10 Sobresaliente con recomendación de publicación.
} 
El conocimiento histórico sobre Prilidiano Pueyrredón comenzó con las acciones de "rescate" impulsadas por Eduardo Schiaffino y José León Pagano en la década de 1930, a lo que le seguirían trabajos como los de Arminda D'Onofrio (1944) o Pagano (1945), quienes marcaron el pulso de las interpretaciones posteriores al revalorizar la imagen del "primer artista nacional". Hacia finales del siglo XX la figura de Pueyrredón fue revisitada, complejizándolo como un agente polifacético de la vida pública porteña de mitad del siglo XIX. Dentro de una significativa literatura sobre el artista, los focos de atención han sido puestos en su producción retratística (Oliver, 1966; Ribera, 1982; Amigo, 2014, entre otros) o sus imágenes sobre desnudos (Malosetti Costa, 1995; Peresan e Iglesias, 2008), mientras que las pinturas de temática rural han recibido mucha menos atención, excepto comentarios en obras de carácter más general o breves referencias en estudios sobre el pintor (Luna, Amigo y Giunta, 1999; Penhos, 2008; Gutiérrez Zaldívar, 2009; Alemán, 2011, entre otros). De allí que, aunque existen numerosos abordajes sobre Pueyrredón, muy pocos han explorado exclusivamente sus pinturas rurales o la dimensión actante de estas. En esta intersección construimos la pesquisa sobre dos ejes centrales: las imágenes y las sensibilidades. Con ello, nuestro objetivo de investigación presentó implicancias no solo históricas sino también metodológicas, aspirando a indagar en otro grado de inteligibilidad respecto de la acción pictórica.

La metodología para profundizar en ello y penetrar en las pinturas estuvo centrada en el paradigma indiciario (Ginzburg, 2013), entendido como procedimiento analítico que permite un acercamiento a la trama pictórica desde múltiples aristas -tanto simbólicas como materiales- ampliando y reduciendo la lente como una forma de reponer la arquitectura de la generalidad iluminando la particularidad del detalle. Por otra parte, y debido a la naturaleza fractal de nuestro objeto, también se efectuaron operaciones de triangulación con fuentes tanto iconográficas como escritas. Estas últimas incluyeron publicaciones periódicas diversas -como El mosquito, El correo del domingo o La revisa de Buenos Aires, por ejemplo- divulgaciones oficiales de distinta índole registros, normativas, actas, cartografías, catastros y censos- y literatura en general diarios de viajes, crónicas y relatos ficcionales. Tal maridaje permitió una exploración del ambiente en el que se gestaron, circularon y consumieron las pinturas, conformando un corpus ecléctico que halló eco en la tesis, con un anexo visual que permitió el diálogo entre "imágenes" y "textos". En términos procedimentales, las pinturas fueron empleadas como un papel de tornasol a través del cual observar problemáticas históricas de relevancia como las formas que asumieron las visualidades, las concepciones de una temprana modernización o la promoción de una nueva sensibilidad. De manera subyacente también pueden entreverse los mecanismos a través de los cuales se edificó un nuevo ordenamiento social y político hacia mediados del siglo XIX, donde el Estado asumió un rol cada vez más destacado (Oszlak, 1982; Bonaudo, 1999; Garavaglia, 2007; Sabato, 2009; Bragoni y Míguez, 2010, entre otros), estimulando un "proceso civilizatorio" (Elías, 1989) que signaría distintas instancias de su recorrido futuro. 
La tesis se compone de once capítulos divididos en tres partes. En la primera, compuesta por tres capítulos, abordamos las dimensiones heurísticas, epistemológicas y metodológicas que sustentan la indagación, comprendiendo desde el estado del arte hasta definiciones conceptuales, pasando por el posicionamiento historiográfico, el material empírico empleado y las operaciones efectuadas en su tratamiento.

Conviene enfatizar que las pinturas que configuran nuestro corpus fueron elaboradas durante la década de 1860, incrustándose en una atmósfera inestable signada por un espíritu de mancomunión, y al mismo tiempo, por diversos proyectos de país (Halperín Donghi, 1982). Ambiente marcado por las controversias, en cuyo seno se promocionó una visión modernizante teñida de una creciente apertura hacia el exterior, la incorporación de tecnologías innovadoras, la reconfiguración de los sitios de tránsito e intercambio, la ampliación del juego político, la explosión asociativa y las modificaciones de la cultura visual como nodos preponderantes (Sabato, 1998; Gayol, 2000; Giunta, 2006; González Bernaldo, 2008; Caimari, 2018, entre otros). De estos aspectos damos cuenta en el capítulo 4, colocando la producción en una atmósfera de modificaciones y novedades de la cultura visual hacia mediados del siglo XIX. En el capítulo siguiente recomponemos la trayectoria formativa de Pueyrredón, con especial atención a las acciones que lo convirtieron en un agente cultural relevante de aquel Buenos Aires. El capítulo 6 ahonda en sus pinturas y en los perfiles de un individuo comprometido con la realidad local, colocándolo como un miembro de lo que Tulio Halperín Donghi (1985) denominó como "vanguardia terrateniente", es decir, un grupo urbano que pretendía instalar los intereses del mundo rural en el seno de la ciudad.

En esta atmósfera de reconfiguraciones y disputas urbanas, las producciones de nuestro artista expusieron paisajes, usos y costumbres de la campaña con una visión que nos permite escrutar a contrapelo los modos de ver de la ciudad. Este aspecto se aborda en la tercera parte de la tesis, procediendo al estudio indiciario de las pinturas en base a su horizonte de posibilidades, sentidos y discursividades. En los capítulos 7 y 8 se examina el despliegue público y privado de una concreción de modales "civilizados" a través de estas pinturas, deplorando la soltura de lo destemplado en pos de una depuración del comportamiento compuesta por el disciplinamiento y la contención, e invocando pautas de limpieza y decoro, claves de bóveda de las nuevas prerrogativas. En los dos últimos capítulos se invierte la lente para examinar las telas desde una traza más amplia, exponiendo en el noveno capítulo un análisis de las características físicas de las obras, como una puerta de entrada al fenómeno de la ampliación de horizontes de una comunidad que se pensaba a sí misma en múltiples conexiones, tanto internas como externas. En el último capítulo recuperamos la metodología de trabajo de nuestro artista como medio para penetrar en la yuxtaposición de escalas de un escenario cultural modernizante, donde coexistieron lo micro y lo macro, el movimiento y la detención, el instante y la eternidad.

Por lo expuesto a lo largo de la tesis y en base a la relación que se devela tanto en el interior de las obras como en su relación con otras fuentes, se concluye que más que 
ilustraciones o retratos costumbristas, estas pinturas operaron como dispositivos complejos con voluntad de expresar las aspiraciones de un grupo urbano sobre una parte de la comunidad, favoreciendo la mancomunión en un contexto efervescente que promovía, en no pocas veces, la discordia. Esto explicaría por qué sus trabajos perfilan una depuración del arreglo externo y la conducta, como marcas que activan una nueva gestión de los escrúpulos, las presentaciones y la violencia. En estas piezas rurales se fomenta no solo un "nuevo orden político" (Bragoni y Míguez, 2010) sino además una pacífica vida comunitaria, una suerte de Arcadia pampeana. Análogamente, las pinturas permiten deconstruir operaciones bajo las cuales la "modernidad" configuró una nueva cultura visual, cuyos atributos centrales se caracterizaron por la ampliación de los horizontes de referencia y la atención al detalle. Estas razones nos muestran las telas de Pueyrredón como "actos icónicos" tendientes a establecer criterios de diferenciación y promoción de nuevas perspectivas. Tanto las imágenes como el universo sociocultural en el que se insertaron, sitúan a Pueyrredón como un "maravilloso ejemplo" en el que coexistieron aspectos sutilmente advertidos por Gutiérrez (1865) al ponderar al pintor como alguien capaz de captar esa doble dimensión con que se imaginó la modernidad: lo perenne y lo fugaz como las "estrellas y amapolas", encarnadas en pinturas que promovieron una nueva sensibilidad en el Buenos Aires de 1860. No fue una instancia definitiva sino un proceso que acababa de comenzar, una suerte de caja de Pandora cuyo alcance y magnitud nos abre nuevos interrogantes con miras a indagaciones futuras.

\section{Referencias bibliográficas}

Alemán, J. (2011). Prilidiano Pueyrredón. Buenos Aires: Arte Gráfico.

Amigo, R. (2014). Pintura Republicana: Colección del Museo Pueyrredón. San Isidro: Municipalidad de San Isidro.

Barrán, J. (1990). Historia de la sensibilidad en el Uruguay. Tomo 2: El disciplinamiento (18601920). Montevideo: Ediciones de la Banda Oriental.

Baxandall, M. (1978). Pintura y vida cotidiana en el Renacimiento. Arte y experiencia en el Quatrocento. Barcelona: Gustavo Gili.

Bonaudo, M. (Dir.) (1999). Nueva Historia argentina, Tomo IV: Liberalismo, estado y orden burgués (1852-1880). Buenos Aires: Sudamericana.

Bragoni, B. y Míguez, E. (2010). Un nuevo orden político. Provincias y Estado nacional, 1852-1880. Buenos Aires: Biblos.

Bredekamp, H. (2017). Teoría del acto icónico. Madrid: Akal.

Burke, P. (2005). Visto y no visto. El uso de la imagen como documento histórico. Barcelona: Crítica.

Burke, P. (2008). Cómo interrogar a los testimonios visuales. En Palos, J. L. y Carrió Invernizzi, D. (Dirs.), La Historia imaginada. Construcciones visuales del pasado en la Edad Moderna (pp. 29-40). Madrid: Centro de Estudios Europa Hispánica. 
Caimari, L. (2018). En el mundo-barrio. Circulación de noticias y expansión informativa en los diarios porteños del siglo XIX. Boletín del Instituto de Historia Argentina y Americana "Dr. Emilio Ravignani", Tercera serie, 49, 81-116.

Corbin, A. (1987). El perfume o el miasma. El olfato y lo imaginario social. Siglos XVIII y XIX. México: Fondo de Cultura Económica.

D'Onofrio, A. (1944). La época y el arte de Prilidiano Pueyrredón. Buenos Aires: Sudamericana.

Elías, N. (1989). El proceso de la civilización. Investigaciones sociogenéticas y psicogenéticas. México: Fondo de Cultura Económica.

Farge, A. (2008). Efusión y tormento. El relato de los cuerpos. Historia del pueblo en el siglo XVIII. Madrid: Katz.

Garavaglia, J. C. (2007). Construir el Estado e inventar la nación: el Río de la Plata, siglos XVIIXIX. Buenos Aires: Prometeo.

Gayol, S. (2000) Sociabilidad en Buenos Aires. Hombres, honor y cafés 1862-1910. Buenos Aires: Del signo.

Ginzburg, C. (2013). Mitos, emblemas e indicios. Morfología e historia. Buenos Aires: Prometeo.

Giunta, R. (2006). La gran aldea y la revolución industrial: Buenos Aires 1860-1870. Buenos Aires: El autor.

González Bernaldo, P. (2008). Civilidad y política en los orígenes de la nación argentina. Las sociabilidades de buenos Aires, 1829-1862. Buenos Aires: Fondo de Cultura Económica.

Gutiérrez Zaldívar, I. (2009). El arte de los argentinos. Prilidiano Pueyrredón. Buenos Aires: Atlántida.

Gutiérrez, J. (1865). Un cuadro de Pueyrredón. Correo del domingo, 70, Buenos Aires.

Halperín Donghi, T. (1982). Una nación para el desierto argentino (1846-1876). Caracas: Biblioteca Ayacucho.

Halperín Donghi, T. (1985). José Hernández y sus mundos. Buenos Aires: Sudamericana.

Luna, F., Amigo, R. y Giunta, P. (1999). Prilidiano Pueyrredón. Buenos Aires: Banco Velox.

Malosetti Costa, L. (1995). Los desnudos de Prilidiano Pueyrredón como punto de tensión entre lo público y lo privado. Ponencia presentada en las $6^{\circ}$ Jornadas de Teoría e Historia de las Artes. Centro Argentino de Investigadores de Arte, Buenos Aires.

Mitchell, W. (2005). ¿Qué quieren las imágenes? Una crítica de la cultura visual. Buenos Aires: Sans Soleil.

Oliver, S. (1966). Argentina en el arte: El retrato en el siglo XIX. Buenos Aires: Viscontea.

Oszlak, O. (1982). La formación del Estado argentino. Buenos Aires: Editorial de Belgrano.

Pagano, J. L. (1945). Prilidiano Pueyrredón. Buenos Aires: Academia Nacional de las Artes.

Penhos, M. (2008). Modelos globales frente a espacios locales: tensiones en la obra de dos artistas europeos en la Argentina del siglo XIX. Studi Latinoamericani, 4, 1-10.

Peresan, A. e Iglesias, A. (2008). Desnudo subjetivo, aproximaciones contextuales y plásticas a la obra El baño de Prilidiano Pueyrredón. AdVersus, 5 (12), 133-151. 
Ribera, A. (1982). El retrato en Buenos Aires, 1580-1870. Buenos Aires: Universidad de Buenos Aires.

Sabato, H. (1998). La politica en las calles. Entre el voto y la movilización. Buenos Aires, 18621880. Buenos Aires: Sudamericana.

Sabato, H. (2009). Historia de la Argentina, 1852-1890. Buenos Aires: Siglo XXI.

Vigarello, G. (1991). Lo limpio y lo sucio. La higiene del cuerpo desde la Edad Media. Madrid: Alianza.

Para citar este resumen:

Masán, Lucas Andrés (2021). Resumen de tesis: “Estrellas y amapolas. Las pinturas rurales de Prilidiano Pueyrredón y las sensibilidades en el Buenos Aires de 1860". Anuario de la Escuela de Historia Virtual, 19, 157-162. 